\title{
Prevalence of goiter and associated factors among schoolchildren in northeast Ethiopia
}

\author{
Emebet Tigabu', Kindie Bantie Bekele², Berihun Assefa Dachew² \\ ${ }^{1}$ Ethiopian Paediatric Association, Amhara Region, Bahir Dar, Ethiopia; ${ }^{2}$ Department of Epidemiology and Biostatistics, Institute of Public \\ Health, College of Medicine and Health Sciences, University of Gondar, Gondar, Ethiopia
}

OBJECTIVES: Goiter is a major public health problem, especially in developing countries such as Ethiopia. Hence, this study aimed to assess the prevalence and associated factors of goiter among children in Waghimra Zone, northeast Ethiopia.

METHODS: A cross-sectional study was conducted from April 8 to 25, 2015 in northeast Ethiopia. A multistage sampling method was used to select 454 schoolchildren. Data were collected using a pre-tested structured interviewer-administered questionnaire. Children were examined for the presence or absence of goiter based on the criteria of the United Nations Children's Fund, International Council for the Control of Iodine Deficiency, and the World Health Organization. Salt samples from children's homes were tested for iodine levels using a rapid iodized salt test kit. Data were entered into EpiInfo version 7 and exported to SPSS version 20 for analysis. Bivariate and multivariate logistic regression models were fitted, and adjusted odds ratio (aOR) with 95\% confidence interval (CI) were computed to determine the level of significance.

RESULTS: The prevalence of goiter was 62.1\% (95\% CI, 57.5 to 66.5\%). Being female (aOR, 3.09; 95\% CI, 1.57 to 6.08), having a family history of goiter (aOR, 5.18; 95\% CI, 2.43 to 11.03), and using non-iodized salt (aOR, 2.20; 95\% CI, 1.12 to 4.38 ) were factors associated with goiter among schoolchildren.

CONCLUSIONS: The prevalence of goiter was high. Being female and having a family history of goiter increased the risk of goiter in children, but using iodized salt was protective. Therefore, we recommend ensuring universal access to iodized salt and increasing the awareness of the community of the importance of iodized salt utilization.

KEY WORDS: Goiter, Prevalence, Risk factors, Ethiopia

\section{INTRODUCTION}

Iodine is one of the essential micronutrient components of the thyroid hormones (thyroxin and triiodothyroxine), which regulate physical and mental development in children [1]. Low blood levels of iodine lead to an insufficient production of these hor-

\section{Correspondence: Berihun Assefa Dachew}

Department of Epidemiology and Biostatistics, Institute of Public Health, College of Medicine and Health Sciences, University of Gondar, P.O. Box 196, Gondar, Ethiopia

E-mail: berihunassefa21@gmail.com

Received: Jul 26, 2017 / Accepted: Nov 25, 2017 / Published: Nov 25, 2017

This article is available from: http://e-epih.org/

(c) This is an open-access article distributed under the terms of the Creative Commons Attribution License (http://creativecommons.org/licenses/by/4.0/) which permits unrestricted use, distribution, and reproduction in any medium, provided the original work is properly cited.

(C) 2017, Korean Society of Epidemiology mones in the body, resulting in iodine deficiency disorder (IDD) [1].

Globally, $30 \%$ of the world's population is affected by IDD $[2,3]$. Goiter, an indicator of chronic iodine deficiency, is a major public health problem in several areas of the world [4]. A study based on the World Health Organization (WHO) global database showed that the total goiter prevalence (TGP) of Africa was $28.3 \%$ [5].

Ethiopia is among the most iodine-deficient countries in the world [6]. A nationwide study conducted in Ethiopia revealed that the TGP in schoolchildren was 39.9\% [7]. However, IDD is the easiest and cheapest of all disorders to prevent. The most effective solution to this problem is the application of universal salt iodization $[3,8]$, which is the most effective, low-cost, and long-term solution that should be deployed on a daily basis, especially in iodine-deficient environments [2]. Ethiopia endorsed a universal salt iodization program with the goal of reaching more than $90 \%$ coverage [9]. An Ethiopian Public Health Institute report found 
that over $88 \%$ of the salt in the country contained iodine, but only $23.2 \%$ of the households used adequately iodized salt [10].

School-age children are the preferred group for inspection and palpation for goiter and IDD surveillance because of their high vulnerability, ease of access, and the high effectiveness of the treatment in this population. Additionally, their iodine status is a proxy for the iodine status of the general population. Various studies have indicated that the prevalence of goiter in children is an indicator of local iodine consumption and is a signal of to what extent the community is affected by the disorder [3-5]. Therefore, investigating the prevalence of goiter is of paramount significance, although there is a dearth of literature on this topic, particularly in the area analyzed in this study. Thus, this study aimed to determine the prevalence of goiter and associated factors among school-age children in Waghimra Zone, northeast Ethiopia.

\section{MATERIALS AND METHODS}

This school-based cross-sectional study was conducted from April 8 to 25, 2015 among children aged 7-12 years in Gasgibla woreda, Waghimra Zone, northeast Ethiopia. This woreda is located $755 \mathrm{~km}$ from Addis Ababa and $561 \mathrm{~km}$ from the regional capital of Bahir Dar.

The sample size was determined by a single-population proportion formula using the EpiInfo program (Centers for Disease Control and Prevention, Atlanta, GA, USA) using the following assumptions: population size, $95 \%$ confidence interval (CI), 5\% marginal error, and $59.1 \%$ prevalence of goiter (which was taken from another similar study) [11]. Considering a 5\% non-response rate and a design effect of 1.5, the required sample size was 454. Multistage sampling followed by a systematic random sampling technique was employed to select study participants. Out of the government-owned primary schools in the study area, 4 (20\%) were selected by simple random sampling. By using the student registration list as a sampling frame, systematic random sampling was applied to select participants from each school.

An interviewer-administered structured questionnaire was used to collect the data. The questionnaire was first prepared in English, translated into the local language (Amharic) and finally, back-translated to English to maintain consistency. Two emergency surgeons (for the physical examination) and 4 nurses were recruited to collect the data. Only the physical examination was directly done with each child, while the rest of the information was collected from the mother/caregiver of the child. A day before data collection, the name, age, sex, and residence of the students were identified from the school register.

A physical examination was performed at school to identify the presence and absence of goiter in accordance with the criteria of the United Nations Children's Fund, International Council for the Control of Iodine Deficiency, and the WHO [12]. The child's neck was inspected and then palpated for abnormal masses. Goiter was considered to be absent if no palpable or visible goiter was present (grade 0 ), whereas goiter was considered to be present when a child had grade 1 or grade 2 goiter, or both. Data on dietary habits and major goitrogenic food items in the locality, such as millet, cow milk, cabbage, and sorghum, were also collected.

On the day of the physical examination, the children included in the study were instructed to bring a pinch of the salt used at their home. The iodine content of the sampled salt was estimated using a rapid iodized salt test kit (MBI test kit; MBI Kits International, Tamil Nadu, India). The kit contained a stabilized starchbased solution that causes a chemical reaction manifested by a color change. The salt sample was taken in a teaspoon, and a drop of the test solution was poured on the salt [13]. Salt samples with less than 15 parts per million (ppm) of iodine content were classified as having inadequate iodine [14].

After checking for completeness, data were entered into EpiInfo version 7 (Centers for Disease Control and Prevention) and exported to SPSS version 20 (IBM Corp., Armonk, NY, USA) for analysis. Descriptive statistics, including frequencies and proportions, were used to summarize the variables. Both bivariate and multivariate logistic regression analyses were performed. A p-value of 0.2 was used as a screening criterion for including variables in the multivariable model. In the multivariate analysis, a p-value of $\leq 0.05$ was considered to indicate statistical significance. The variables were entered into the multivariate model using the forward stepwise regression method.

Ethical clearance was obtained from the institutional review board of the Bahir Dar University Institute of Technology. An official permission letter was secured from the Amhara Regional Health Bureau Research Centre. The confidentiality of the information was maintained. Written or verbal (for those who could not read or write) consent was obtained from each mother/guardian. Assent was obtained from children before palpating their thyroid gland. Children who were found to have goiter were referred to a health institution to receive appropriate treatment and support.

\section{RESULTS}

\section{Socio-demographic characteristics}

A total of 443 children with a mother/caregiver participated in the study, corresponding to a response rate of $97.6 \%$. More than half $(54.0 \%)$ of them were females, with a mean age of $9.77 \pm 1.74$ years. Regarding the socio-demographic characteristics of the mothers/caregivers, the majority were married $(78.8 \%)$ and $38.1 \%$ were farmers by occupation. Table 1 shows the socio-demographic characteristics of the children and their mothers / caregivers in the study area.

\section{Dietary habit and goitrogenic food consumption by children}

Most of the children (89.6\%) had a history of eating sorghum frequently; $76.0 \%$ of them consumed it daily. The second most commonly consumed goitrogenic staple food was millet, which was reported to be consumed more than once per month by 101 
Table 1. Socio-demographic characteristics of children and their mothers/caregivers in Gasgibla woreda, Waghimra Zone, northeast Ethiopia, 2015

\begin{tabular}{lc}
\hline Variables & $\mathrm{n}(\%)$ \\
\hline Child characteristics & \\
Age $(\mathrm{yr})$ & $192(43.3)$ \\
$7-9$ & $251(56.7)$ \\
$10-12$ & \\
Sex & $239(54.0)$ \\
Female & $204(46.0)$ \\
Male & \\
Characteristics of mothers/caregivers & \\
Marital status & $349(78.8)$ \\
Married & $40(9.0)$ \\
Divorced & $34(7.7)$ \\
Single & $20(4.5)$ \\
Widowed & \\
Educational status & $225(50.8)$ \\
Cannot read and write & $164(37.0)$ \\
Read and write & $35(7.9)$ \\
Elementary & $13(2.9)$ \\
Secondary & $6(1.3)$ \\
Above secondary & \\
Occupational status & $193(43.6)$ \\
Housewife & $169(38.1)$ \\
Farmer & $49(11.1)$ \\
Merchant & $10(2.3)$ \\
Civil servant & $22(5.0)$ \\
Others ${ }^{1}$ &
\end{tabular}

'Daily laborer, private worker.

of the children (22.8\%). Among vegetables and dairy products, cabbage and milk were consumed by 347 (78.3\%) and 170 (38.4\%) of the children, respectively, and rivers were the source of drinking water for $26.9 \%$ of the children (Table 2).

\section{Knowledge and utilization of iodized salt by mothers}

In this study, 245 mothers (55.3\%) were aware of iodized salt, but only 150 (61.2\%) used iodized salt. The common reasons mentioned by the respondents for not using iodized salt were unavailability and cost, which were reported by 54 (56.8\%) and 37 (39.0\%) of them, respectively. Only $17.2 \%$ of the households used salt with an adequate iodine level ( $\geq 15 \mathrm{ppm}$ ) (Table 3$)$.

\section{Prevalence of goiter and factors independently associated with goiter}

The overall prevalence of goiter in schoolchildren (7-12 years) was found to be $62.1 \%$ (95\% CI, 57.5 to $66.5 \%$ ). Logistic regression analysis was carried out for socio-demographic and other characteristics, including age, sex, dietary habits, knowledge of iodized salt, and its consumption at the household level. In the bivariate logistic regression, the child's age, sex, place of birth, io-
Table 2. Dietary habit and goitrogenic food consumption of children aged 7-12 years in Gasgibla woreda, Waghimra Zone, northeast Ethiopia, 2015

\begin{tabular}{lc}
\hline Variables & Frequency (\%) \\
\hline Sorghum consumption $(n=388)$ & \\
At least once per day & $329(76.0)$ \\
At least once per week & $32(7.4)$ \\
At least once per month & $27(6.2)$ \\
Millet consumption $(n=101)$ & \\
At least once per day & $32(7.2)$ \\
At least once per week & $10(2.3)$ \\
At least once per month & $59(13.3)$ \\
Cabbage consumption $(n=347)$ & \\
At least once per day & $31(7.0)$ \\
At least once per week & $187(42.2)$ \\
At least once per month & $129(29.1)$ \\
Milk consumption ( $n=170)$ & \\
At least once per day & $19(4.3)$ \\
At least once per week & $100(22.6)$ \\
At least once per month & $51(11.5)$ \\
Source of drinking water $(n=433)$ & \\
Pipe & $324(73.1)$ \\
River & $119(26.9)$ \\
\hline
\end{tabular}

Table 3. Knowledge and utilization of iodized salt by mothers in Gasgibla woreda, Waghimra Zone, northeast Ethiopia, 2015

\begin{tabular}{lc}
\hline Variables & $\mathrm{n}(\%)$ \\
\hline $\begin{array}{l}\text { Do you know about iodized salt? } \\
\text { Yes }\end{array}$ & $245(55.3)$ \\
No & $198(44.7)$ \\
If yes, do you use it? & \\
Yes & $150(61.2)$ \\
No & $95(38.8)$ \\
If yes, when do you add iodized salt? & \\
During cooking & $81(54.0)$ \\
After cooking & $65(43.3)$ \\
Cannot remember & $4(2.7)$ \\
Reason for not using iodized salt & \\
Lack of access & $54(56.8)$ \\
Cost & $37(39.0)$ \\
Other & $4(4.2)$ \\
lodine level of salt (ppm) & \\
0 & $269(60.7)$ \\
$<15$ & $98(22.1)$ \\
$15-30$ & $76(17.2)$ \\
\hline
\end{tabular}

ppm, parts per million.

${ }^{1}$ No difference, not tasty.

dized salt utilization, and family history of goiter were associated with goiter. However, in the final multivariate logistic regression, only the child's sex, family history of goiter, and iodized salt utili- 
Table 4. Factors associated with goiter among schoolchildren, Gasgibla woreda, Waghimra Zone, northeast Ethiopia, 2015

\begin{tabular}{|c|c|c|c|c|}
\hline \multirow{2}{*}{ Variables } & \multicolumn{2}{|c|}{ Goiter } & \multirow{2}{*}{ OR $(95 \% \mathrm{Cl})$} & \multirow{2}{*}{ aOR $(95 \% \mathrm{Cl})^{1}$} \\
\hline & Yes & No & & \\
\hline \multicolumn{5}{|l|}{ Age (yr) } \\
\hline $7-9$ & 104 & 88 & 1.00 (reference) & \\
\hline $10-12$ & 171 & 80 & $1.81(1.23,2.67)$ & \\
\hline \multicolumn{5}{|l|}{ Sex } \\
\hline Male & 103 & 101 & 1.00 (reference) & 1.00 (reference) \\
\hline Female & 172 & 67 & $2.52(1.67,3.73)$ & $3.09(1.57,6.08)^{*}$ \\
\hline \multicolumn{5}{|c|}{ Place of birth } \\
\hline Zarota & 100 & 46 & 1.00 (reference) & \\
\hline Asketema & 57 & 61 & $1.02(0.59,1.76)$ & \\
\hline Kieta & 47 & 29 & $2.37(1.37,4.12)$ & \\
\hline Bela & 71 & 32 & $1.37(0.73,2.53)$ & \\
\hline \multicolumn{5}{|c|}{ lodized salt utilization } \\
\hline Yes & 81 & 69 & 1.00 (reference) & 1.00 (reference) \\
\hline No & 194 & 99 & $1.67(1.07,3.16)$ & $2.20(1.12,4.38)^{*}$ \\
\hline \multicolumn{5}{|c|}{ Family history of goiter } \\
\hline Yes & 190 & 72 & $2.98(2.01,4.44)$ & $5.18(2.43,11.03)^{*}$ \\
\hline No & 85 & 89 & 1.00 (reference) & 1.00 (reference) \\
\hline
\end{tabular}

OR, odds ratio; $\mathrm{Cl}$, confidence interval; aOR, adjusted $\mathrm{OR}$.

${ }^{1} T$ The forward stepwise regression method was used. ${ }^{*} p<0.05$.

zation were found to be significantly associated with our outcome variable. The probability of developing goiter was about 3 times higher among females (adjusted odds ratio [aOR], 3.09; 95\% CI, 1.57 to 6.08 ) than among males. Children from households that did not use iodized salt were about 2 times more likely to have goiter (aOR, 2.20; 95\% CI, 1.12 to 4.38) than their counterparts. The likelihood of developing goiter was about 5 times greater ( $\mathrm{aOR}$, 5.18; $95 \%$ CI, 2.43 to 11.03 ) among children with a family history of goiter than among children without a family history of goiter (Table 4).

\section{DISCUSSION}

In this study, the prevalence of goiter was determined to be $62.1 \%$. This rate is much higher than the cut-off point of the WHO IDD classification (5.0\%) [4]. This finding is also higher than those of other studies. For example, the Ethiopian national average prevalence was found to be 39.9\% [7], while that of Gondar and Jimma was 37.6\% [15] and 59.1\% [11], respectively. A possible reason for the variations from place to place could be the density of grass. Our study was conducted in an over-grazed and mountainous environment highly exposed to soil erosion, which washes away the iodine in the topsoil, resulting in iodine-deficient food crops and leading to a low level of iodine content in the staple foods of the inhabitants. However, the prevalence we observed is lower than the finding reported in a study conducted in Tigray (71.4\%) [16]. This may be because our study was undertaken after universal salt iodization was launched in Ethiopia.
This study showed that the non-utilization of iodized salt in a household was associated with the development of goiter in children. Non-iodized salt users were about 2 times more likely to have goiter than iodized salt users. This finding is in agreement with the findings of other similar studies $[5,11,17]$. This could be because iodized salt has both preventive and corrective effects for iodine deficiency goiter, and is the main solution for eradicating IDD. The WHO has recommended that $90 \%$ of the households in a population should be able to obtain iodized salt with an iodine level > 15 ppm for the effective elimination of IDD [4]. However, in this study, only 76 households (17.2\%) had adequate salt, with an iodine level $>15 \mathrm{ppm}$. This may have been a primary reason for the high prevalence of goiter in the study area. The low coverage of iodized salt, coupled with a low awareness of the importance of iodized salt, and its high cost are likely the factors that are fueling the high prevalence of goiter.

The prevalence of goiter was higher among females in our study. This finding is consistent with reports from various studies conducted throughout the world $[11,16-18]$. This could be due to the physiological differences between males and females. That is, females start spurt growth earlier than males and require more iodine.

Our study demonstrated a significant association between family history and goiter. Children whose parents had goiter had about a 5-fold increased risk of developing goiter when compared to those who had no family history. This finding is similar to those of other studies $[11,15]$, and could be due to the fact that malnutrition has inter-generational cycles [19]. 
The study has some limitations. Since only schoolchildren were included in this study, the results may not be generalizable to children who are not in school. In addition, there may have been a misclassification bias in the determination of salt iodine levels by the rapid test kit, as other laboratory tests, such as a urinary iodine excretion test, blood tests for thyroid-stimulating hormone, and testing of the iodine levels of water were not done. Finally, although we asked the mothers/caregivers during the interview period to ascertain that the salt brought by the children was truly from their home, we were not able to fully exclude this potential problem.

In summary, the overall prevalence of goiter was found to be high in the present study. In this study, being female and having a family history of goiter were associated with an increased risk of goiter in children. In contrast, using iodized salt was found to be a protective factor against goiter. The risks and consequences of IDD should be emphasized, and programs aimed at the prevention and control of IDD should gain attention at all levels. Ensuring universal accessibility and availability of iodized salt at the household level is strongly recommended. Further research with a better methodological design, including laboratory methods to determine the iodine content of water and urinary iodine excretion, is recommended.

\section{ACKNOWLEDGEMENTS}

The authors would like to acknowledge Bahir Dar University for ethical clearance. We would also like to thank the study participants, data collectors, and supervisors for their dedicated cooperation.

\section{CONFLICT OF INTEREST}

The authors have no conflicts of interest to declare for this study.

\section{ORCID}

Emebet Tigabu: https://orcid.org/0000-0001-6054-0226; Berihun Assefa Dachew: https://orcid.org/0000-0002-4041-6129

\section{REFERENCES}

1. Gunnarsdottir I, Dahl L. Iodine intake in human nutrition: a systematic literature review. Food Nutr Res 2012;56:19731.

2. Ministry of Health of Ethiopia. National guideline for control and prevention of micronutrient deficiencies. Addis Ababa: Federal Ministry of Health; 2004, p. 13-26.

3. World Health Organization. Goitre as a determinant of the prevalence and severity of iodine deficiency disorders in populations; 2014 [cited 2017 Dec 11]. Available from: http://www.who.int/ vmnis/indicators/goitre_idd/en/.

4. World Health Organization. Assessment of iodine deficiency disorders and monitoring their elimination: a guide for programme managers; 2007 [cited 2017 Dec 11]. Available from: http://apps. who.int/iris/bitstream/10665/43781/1/9789241595827_eng.pdf.

5. Andersson M, Takkouche B, Egli I, Allen HE, de Benoist B. Current global iodine status and progress over the last decade towards the elimination of iodine deficiency. Bull World Health Organ 2005;83:518-525.

6. Andersson M, Karumbunathan V, Zimmermann MB. Global iodine status in 2011 and trends over the past decade. J Nutr 2012; 142:744-750.

7. Abuye C, Berhane Y, Akalu G, Getahun Z, Ersumo T. Prevalence of goiter in children 6 to 12 years of age in Ethiopia. Food Nutr Bull 2007;28:391-398.

8. Zhao W, Han C, Shi X, Xiong C, Sun J, Shan Z, et al. Prevalence of goiter and thyroid nodules before and after implementation of the universal salt iodization program in mainland China from 1985 to 2014: a systematic review and meta-analysis. PLoS One 2014;9:e109549.

9. Global Alliance for Improved Nutrition. Ethiopia universal salt iodization [cited 2017 Dec 12]. Available from: https://www.gainhealth.org/knowledge-centre/project/ethiopia-universal-salt-iodization/.

10. Ethiopian Public Health Institute. National salt iodization coverage towards prevention of iodine deficiency disorder in Ethiopia; 2014 [cited 2017 Dec 12]. Available from: https://www.ephi.gov. et/images/pictures/USI\%20presentation_Forum_October_25_ 2014.pdf.

11. Mezgebu Y, Mossie A, Rajesh P, Beyene G. Prevalence and severity of iodine deficiency disorder among children 6-12 years of age in Shebe Senbo district, Jimma zone, southwest Ethiopia. Ethiop J Health Sci 2012;22:196-204.

12. World Health Organization. Indicators for assessing iodine deficiency disorders and their control programmes: report of a joint WHO/UNICEF/ICCIDD consultation; 1993 [cited 2017 Dec 12]. Available from: http://www.who.int/nutrition/publications/ micronutrients/iodine_deficiency/WHO_NUT_93.1/en/.

13. MBI KITS. The MBI kit [cited 2017 Dec 12]. Available from: http://www.mbikits.com/the-mbi-kit/.

14. Pandav CS, Arora NK, Krishnan A, Sankar R, Pandav S, Karmarkar MG. Validation of spot-testing kits to determine iodine content in salt. Bull World Health Organ 2000;78:975-980.

15. Mesele M, Degu G, Gebrehiwot H. Prevalence and associated factors of goiter among rural children aged 6-12 years old in Northwest Ethiopia, cross-sectional study. BMC Public Health 2014; 14:130.

16. Kidane T, Woldegebriel A. Prevalence of Iodine deficiency disorder in a highland district in Tigray. Ethiop J Health Dev 2006;20: 58-59.

17. Hailu S, Wubshet M, Woldie H, Tariku A. Iodine deficiency and associated factors among school children: a cross-sectional study in Ethiopia. Arch Public Health 2016;74:46.

18. Kamath R, Bhat V, Rao RS, Acharya D, Kapil U, Kotian MS, et al. Prevalence of goitre among school children in Belgaum district. Indian J Pediatr 2009;76:825-828.

19. Stagnaro-Green A, Sullivan S, Pearce EN. Iodine supplementation during pregnancy and lactation. JAMA 2012;308:2463-2464. 